\title{
Caracterização de um perfil de solo desenvolvido no sambaqui fluvial Moraes, município de Miracatu - SP ${ }^{1}$
}

\author{
Wenceslau Geraldes Teixeira ** \\ Cláudia Regina Plens*** \\ Rodrigo Santana Macedo**** \\ Levy Figuti****
}

TEIXEIRA, W.G.; PLENS, C.R.; MACEDO, R.S.; FIGUTI; L. Caracterização de um perfil de solo desenvolvido no sambaqui fluvial Moraes, município de Miracatu SP. R. Museu Arq. Etn., São Paulo, n. 22: 181-194, 2012.

Resumo: Escavações arqueológicas desenvolvidas no sambaqui fluvial Moraes, no município de Miracatu, SP, revelaram distintas camadas arqueológicas que resultaram na configuração monticular deste sítio. Com o objetivo de discutir o processo formativo deste sítio, foram realizadas análises físico-químicas do solo de dentro e de fora do mesmo para a compreensão das propriedades que podem ter contribuído para a caracterização das particularidades encontradas nas camadas arqueológicas deste sambaqui fluvial. Foi constatada uma elevada alteração em alguns parâmetros físicos e químicos dos diferentes horizontes do solo desenvolvido no sambaqui. Em especial os elevados teores de fósforo corroboram um enriquecimento deste ambiente em resíduos antrópicos ricos neste elemento (e.g. ossos). Os horizontes escuros também mostram elevados teores de carbono em relação ao perfil testemunho. Entretanto, ainda não está claro se a estabilização do carbono nos sambaquis se deve à estabilização do cálcio ou efeito de calor (carbono pirogênico) e precisará ser elucidado em próximos estudos.

Palavras-chaves: Sambaqui fluvial, Análise de solo, Terra preta de índio, Processo de formação, Caçadores-coletores.

\section{Introdução}

s sambaquis são montes artificiais de di-
mensões variadas (de 50 a 1000 metros de comprimento e de 1 a 30 metros de altura),

(*) Embrapa Solos <wenceslau.teixeira@embrapa.br>

$\left.{ }^{* *}\right)$ Departamento de História da Universidade Federal de São Paulo, UNIFESP, <plens@unifesp.br>

$\left.{ }^{(* *}\right)$ Escola Superior de Agricultura "Luiz de Queiroz", USP, <macedo.rs@usp.br>

${ }^{(* * *)}$ Museu de Arqueologia e Etnologia da Universidade de São Paulo, USP, <lfiguti@usp.br> cujo sedimento é composto por mais de $80 \%$ por conchas de bivalves (Figuti 1991). Os sambaquis costeiros se encontram dispersos em $1500 \mathrm{~km}$ da costa brasileira. Do ponto de vista geomorfológico, a maioria dos sambaquis se encontra em áreas de estuários: áreas de lagoas, zonas de dunas e praias abertas (Plens 2007, 2011).

(1) Parte do Projeto financiado pela Fapesp intitulado "O estudo dos sambaquis fluviais das bacias do médio Juquiá, São Lourenço e do Itariri." Processo no. 05/50078-0. 
Desde o século XIX, o termo sambaqui tem sido empregado para designar os sítios shellmounds encontrados na costa brasileira. Desde então, dois diferentes termos vêm sendo empregados para os sítios que apresentam gastrópodes terrestres na sua composição: concheiros ou sambaquis fluviais. Embora o termo concheiro tenha sido empregado algumas vezes na literatura (Barreto 1988), o termo sambaquis fluviais tem sido preponderante nas descrições. Mais do que isto, de acordo com uma revisão dos conceitos de sambaquis definidos por Prous (1992) e Gaspar (1998), se observa que a definição de sambaquis se refere, sobretudo às estruturas monticulares e seus componentes construtivos (para uma revisão mais detalhada ver Plens 2007).

Os sambaquis fluviais referidos no presente artigo se concentram em áreas específicas do Vale do Ribeira, no estado de São Paulo, como no município de Itaoca (alto e médio vale) e nos seus tributários, como no rio Jacupiranguinha (afluente sul) e rio Juquiá (tributário ao norte).

De acordo com Barreto (1988), a especificidade desta área sugeriria um sistema de assentamento integrado. Por razão da proximidade com grandes rios e por acreditar que as datações eram mais antigas na costa do que no interior, foi sugerida a hipótese de migração da costa para o interior em busca de recursos econômicos.

Barreto também sugeriu como resultado da migração costeira que seria possível encontrar similaridades entre os sambaquis costeiros e fluviais no que se refere ao padrão construtivo, embora em escalas distintas, assim como fauna proveniente da costa. Nos sambaquis fluviais, assim como nos costeiros, também é possível localizar alta densidade de sepultamentos (Figuti et al. 2006; Plens 2007).

Os remanescentes faunísticos encontrados nos sambaquis fluviais são compostos, sobretudo, por conchas de gastrópodes terrestres predominantemente da espécie Megalobulimus spp., ossos e dentes de mamíferos terrestres e peixes de água doce. Aves e répteis estão presentes, porém em menor proporção (Figuti et al. 2004, 2006; Plens 2007, 2009, 2011).

Os sambaquis fluviais também apresentam abundante indústria sobre material faunístico (ossos, dentes, chifres e conchas), grande parte sendo pontas de projéteis e adornos. A indústria lítica também é abundante e é caracterizada por ferramentas lascadas e polidas.

O projeto intitulado "Investigações Arqueológicas e Geomorfológicas dos Sambaquis Fluviais" foi realizado entre 1999 e 2004, sendo desenvolvido por pesquisadores do Museu de Arqueologia e Etnologia, Instituto de Biologia e Instituto de Astronomia e Geofísica da Universidade de São Paulo. Este projeto teve como objetivo investigar os sambaquis fluviais do Vale do Ribeira de Iguape a partir de diferentes perspectivas: arqueológicas, pedológicas, geofísicas e bioarqueológicas. Os resultados sobre estruturas e características culturais deste projeto apontaram para a preferência destes grupos pelo assentamento desses sítios em áreas planas ou baixas, com exceção de alguns poucos sítios localizados no topo de montanhas ou vales distantes de fontes de água de grande porte (Figuti et al., 2006).

De acordo com Figuti et al. (2006), o projeto gerou uma série de datações radiocarbônicas de 18 sítios, para a qual houve preferência por datações do topo de base de sítios das áreas do Jacupiranguinha (5), Itaoca (10), Juquiá (3). Essas datações revelaram três conjuntos cronológicos de ocupação dessas áreas pela construção de sambaquis fluviais:

1 - Os sambaquis mais antigos (9250 a 8500 AP). Estes sítios estão concentrados na área do Jacupiranguinha;

$$
\text { - } 1^{\circ} \text {. Intervalo }-8.500 \text { a } 7000 \mathrm{AP}
$$

(1500 anos);

2 - Expansão dos sambaquis fluviais (7000 a 3500 AP). Datações representadas por nove sítios espalhados pela área de pesquisa;

$$
\text { - 20. Intervalo - } 3500 \text { a } 1700 \text { AP }
$$

(1800 anos);

3 - Período recente dos sambaquis fluviais (1700 a 1200 AP). Datações representadas por sete sítios da área de Itaoca.

\section{O Sítio Moraes}

Propriedade do Sr. Celso Ferreira, este sítio arqueológico é situado na bacia do córrego Moraes, afluente do rio São 
Lourenço, no município de Miracatu cujas coordenadas em UTM são $23 \mathrm{~J}$ 0256908 / 7313340 (Fig.1).

$\mathrm{O}$ reconhecimento deste sítio se deu na década de 1970 pelo pesquisador Caio Del Rio
Garcia, porém sem sofrer intervenções. O sítio apresenta uma elevação com cerca de $30 \mathrm{~m}$ de diâmetro e $2 \mathrm{~m}$ de altura. Atualmente encontra-se coberto por uma vegetação rasteira em meio a um bananal. Aos lados sul e oeste, ele é

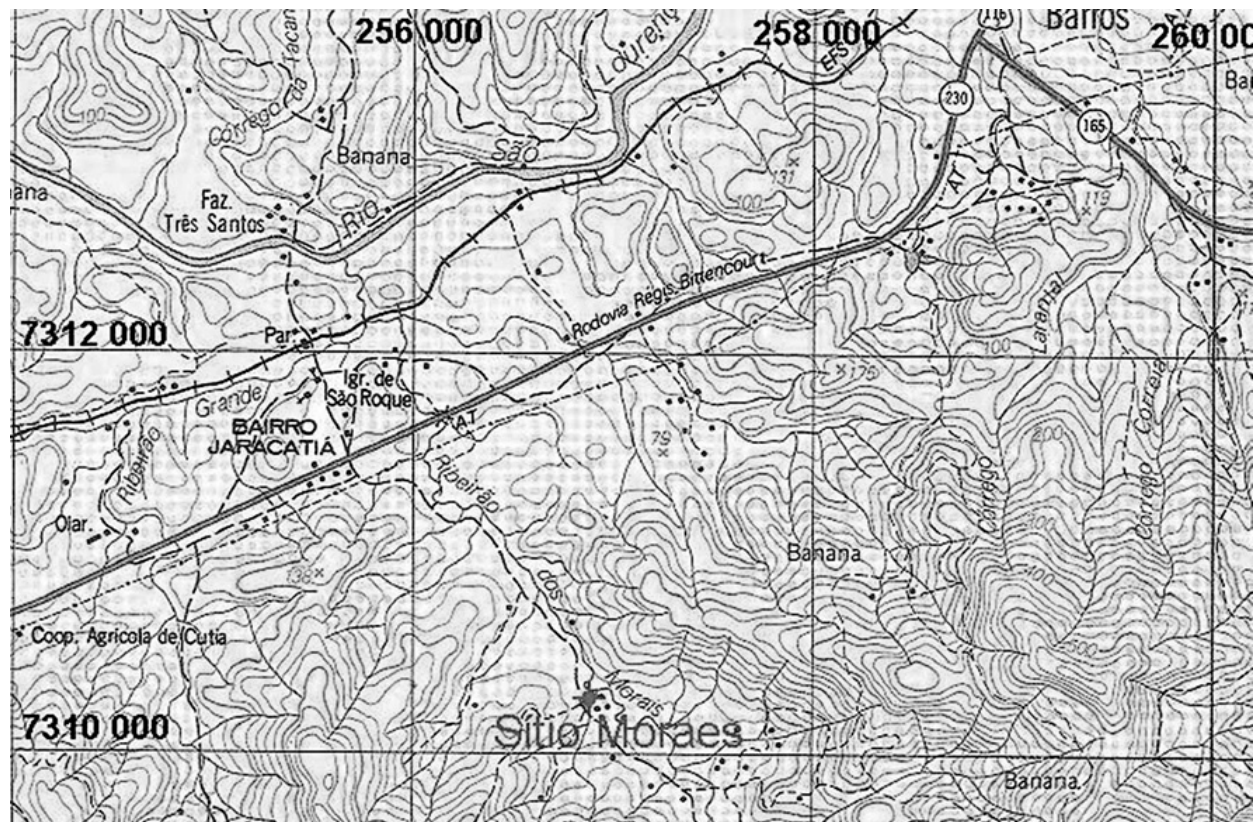

Fig. 1. Detalhe de mapa topográfico do Vale do Ribeira mostrando a localização da área de estudo (Sítio Moraes) (Fonte: Figuti 2006).

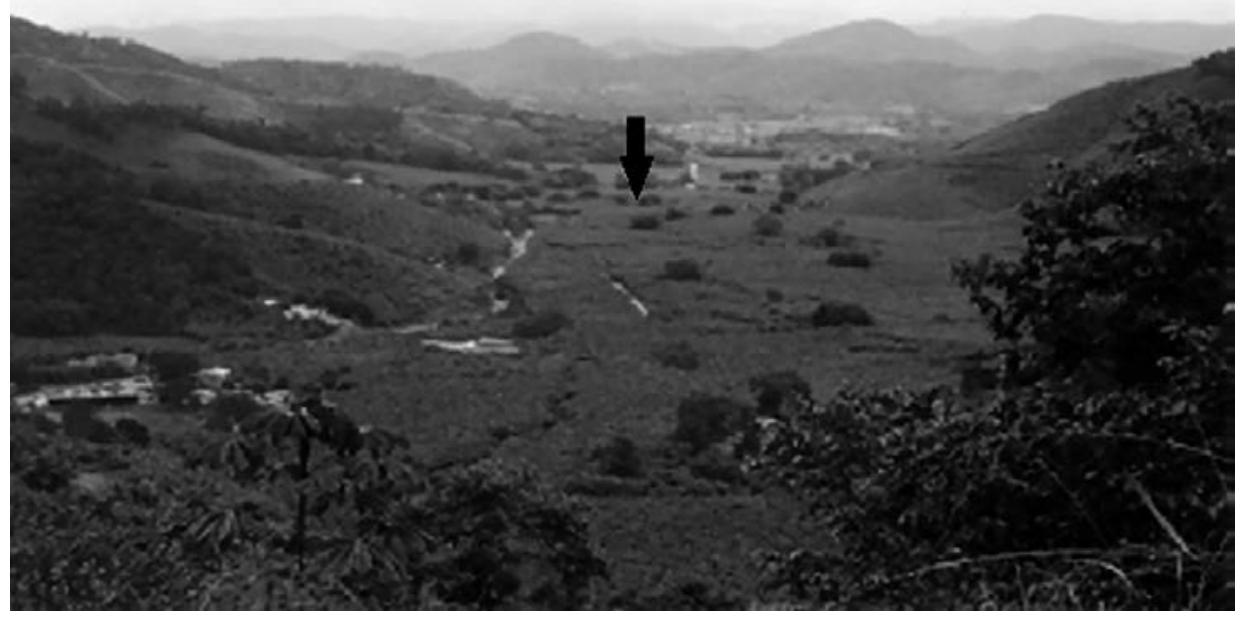

Fig. 2. Vista do Vale do Ribeirão Moraes, seta indicando a localização do sítio arqueológico; a vegetação circundante é um bananal. (Fonte: Figuti 2006). 
delimitado por afloramentos de granito/gnaisse e por uma vala de drenagem; a leste, encontra-se o córrego Moraes e, ao norte, apenas um terreno plano. Na sua porção oeste, sentido norte-sul, existe uma estrada de terra interna da fazenda (Fig.2).

Durante as escavações realizadas no sítio Moraes foi possível perceber que há horizontes escuros de solo que permeiam as conchas sobre os sepultamentos, cuja composição principal é de matéria orgânica, o que remete aos horizontes antrópicos denominados Terra Preta de Índio (TPI) encontrados na bacia amazônica (Teixeira et al. 2010).

O estudo das TPIs encontradas na área amazônica tem demonstrado que esses horizontes antrópicos consistem em depósitos acumulativos formados durante séculos de ocupações contínuas, ou quase contínuas (Heckenberger 2001). Esses horizontes apresentam elevada concentração de nutrientes, tal como fósforo, cálcio, magnésio e zinco, além de elevados estoques de matéria orgânica.

A comparação entre o solo do sítio Moraes e da TPI da área amazônica aqui se refere apenas por ambas apresentarem processos acumulativos antrópicos, porém, certamente possuem características físico-químicas distintas. Além disso, o sítio Moraes apresentou camadas arqueológicas com características físicas distintas macroscopicamente. Tendo em vista a tese de doutoramento que foi desenvolvida a partir das pesquisas realizadas neste sítio (Plens 2007), aventou-se a possibilidade de construir o conhecimento da formação do sítio a partir das características físico-químicas relacionadas com a formação de cada camada arqueológica. $\mathrm{O}$ presente artigo trata, portanto, destes resultados.

\section{Contexto ambiental da área de estudo}

A geologia da região do vale do Ribeira é bastante complexa formada por associações metamórficas como o complexo Embu e complexo Atuba e por deposição de sedimentos fluviais holocênicos nas áreas de várzeas (CPRM 2001).
As classes de solos predominantes na região próxima à cidade de Miracatu onde está localizada a área de estudo foram descritas como Cambissolos distróficos argilosos e de textura média associados com Argissolos textura média/argilosa e Cambissolos argilosos todos com a presença de horizonte A moderado. Outra classe de solo comum nesta região nas áreas com relevo fortemente ondulado são os Argissolos Vermelho-Amarelo, textura muito argilosa / argilosa. Nas áreas próximas aos ribeirões e rios ocorrem os solos acinzentados ou gleisados denominados de Gleissolos argilosos distróficos associados a Cambissolos distróficos e eutróficos (Lepsch et al. 1999). Ocorrem também nesta região, principalmente nas várzeas do baixo e do médio curso do rio Ribeira de Iguape e seus principais afluentes, solos com predominância de sedimentos de origem orgânica, denominados atualmente de Organossolos, tendo sido estimados num total de 135.000 hectares nesta região (Lepsch et al. 1990).

O clima em local próximo à área de estudo foi classificado por Sakay e Lepsch (1987) do tipo Af pela classificação de Koeppen, definido como tropical, quente e úmido, sem estação seca. A precipitação total média anual varia em torno de $1.500 \mathrm{~mm}$. A temperatura média anual é de $22^{\circ} \mathrm{C}$ sendo a diferença entre os meses de verão e inverno superior a $5^{\circ}$.

\section{Material e métodos}

Os perfis foram amostrados e descritos segundo as recomendações e critério do Manual de Levantamento no Campo (Lemos e Santos 1997).

As amostras coletadas e descritas na parte central do perfil do sítio arqueológico (Fig. 3). Além disso, para fins de comparação foi descrito e amostrado um perfil numa área adjacente a aproximadamente uns 500 metros do sítio Moraes para caracterização e classificação do solo predominante nesta área (Fig. 4). Os perfis foram classificados segundo o Sistema Brasileiro de Classificação de Solos (Embrapa 2006). 


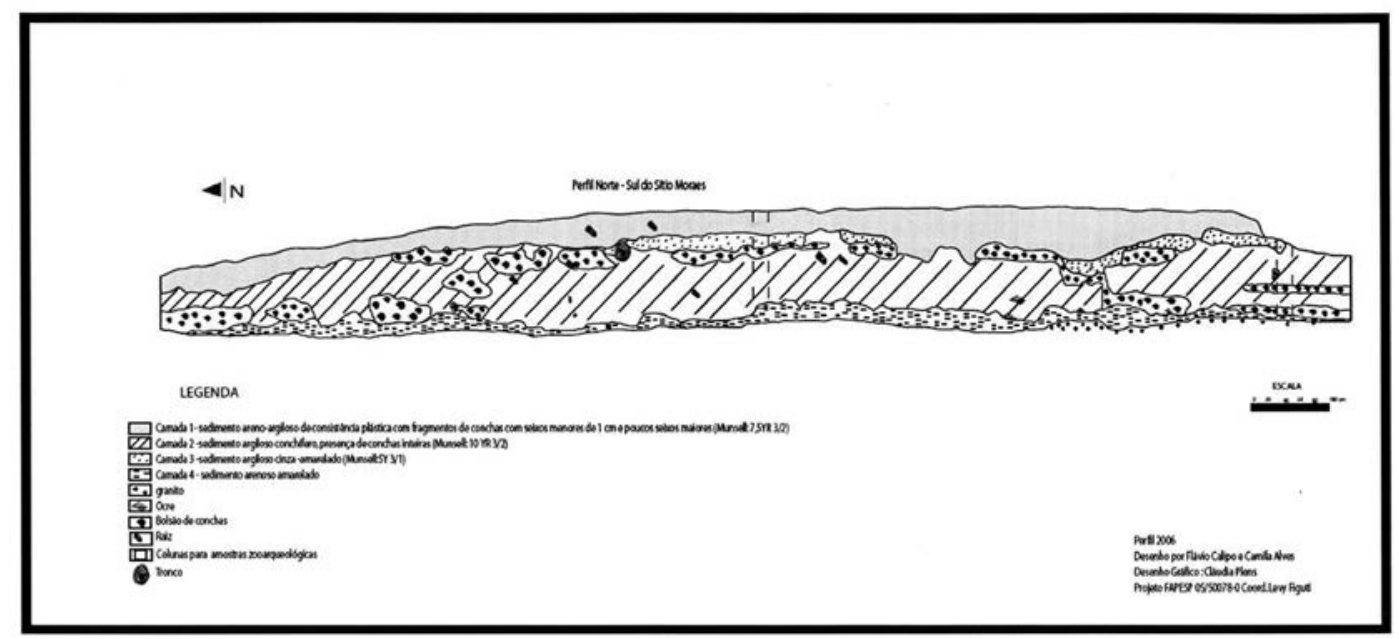

Fig. 3. Perfil do Sítio Moraes.

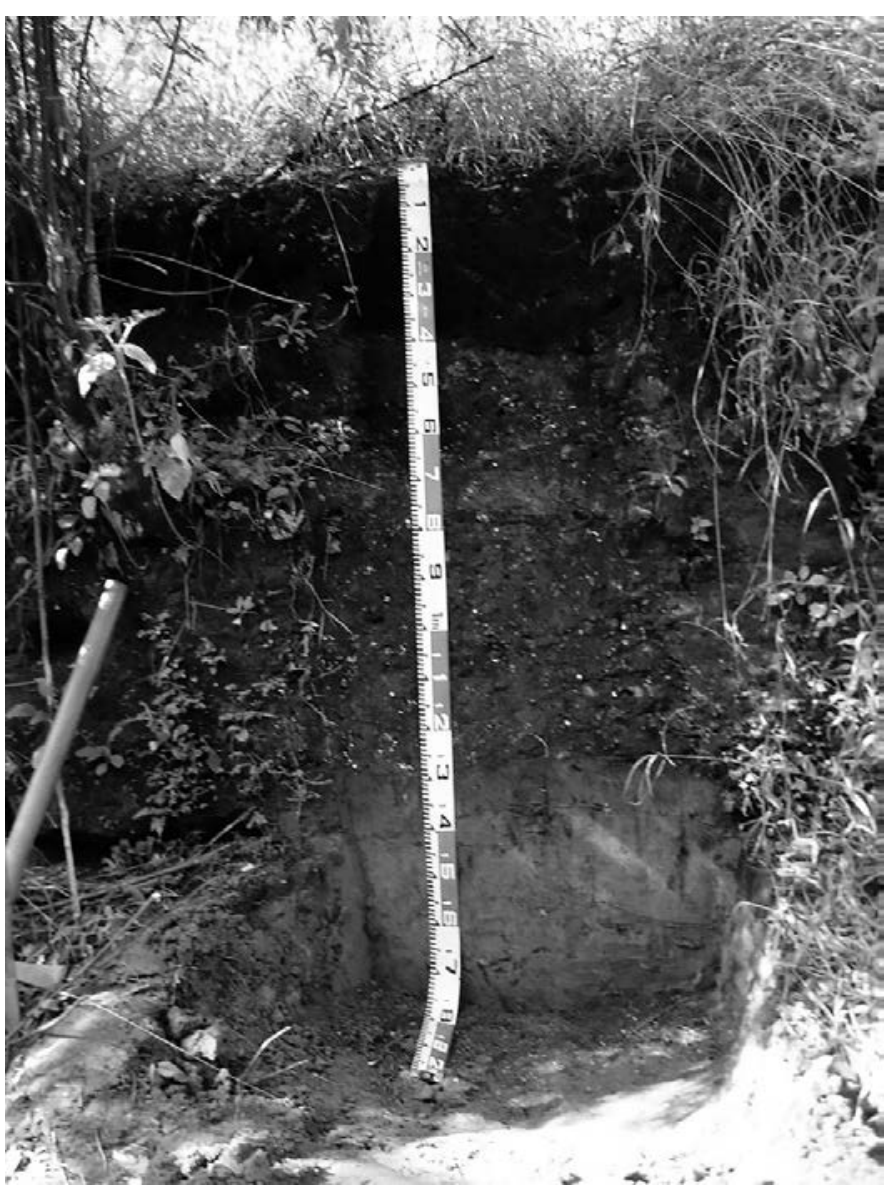

Fig. 4. Perfil amostrado de área adjacente ao Sítio Moraes (Foto: Plens 2007). 
As amostras de solos coletadas nos diferentes horizontes pedológicos foram analisadas nos laboratórios da Embrapa Amazônia Ocidental em Manaus conforme os métodos constantes em Embrapa (1997), que serão brevemente descritos abaixo.

Procedeu-se às determinações analíticas nas amostras após o destorroamento e tamização da amostra total em peneira com $2 \mathrm{~mm}$ de abertura de malha, sendo este material denominado Terra Fina Seca ao Ar (TFSA). Na determinação da composição granulométrica empregou-se $\mathrm{NaOH} \mathrm{N}$ como dispersante e agitação em alta rotação por 20 minutos. As frações areia grossa $(0,2-2 \mathrm{~mm})$ e areia fina $(0,05-0,2 \mathrm{~mm})$ foram obtidas por tamização, a fração argila $(<0,002$ $\mathrm{mm}$ ) foi determinada por pesagem por amostra obtida utilizando o método da pipeta (Leis de Stokes), e a fração silte $(0,002-0,05 \mathrm{~mm})$ foi obtida por diferença entre as somas das frações areia e argila da massa total da amostra. Pelo mesmo procedimento, com substituição do dispersante químico por água destilada, determinou-se o teor de argila dispersa em água.

Os valores de $\mathrm{pH}$ em água foram medidos com eletrodo de vidro, em suspensão solo-líquido na proporção 1:2,5; o conteúdo de carbono (C) orgânico foi determinado por oxidação da matéria orgânica pelo bicromato de potássio 0,4 $\mathrm{N}$ em meio sulfúrico e titulação por sulfato ferroso 0,1 N (Método Walkley-Black). O fósforo assimilável (P assim.) foi extraído com solução de $\mathrm{HCl}$ 0,05 N e H2SO4 0,025 N (Melhich I - Carolina do Norte) e dosado colorimetricamente pela redução do complexo fosfomolibdico com ácido ascórbico, em presença de sal de bismuto. Com solução de $\mathrm{KCl} \mathrm{N}$ na proporção 1:20 foram extraídos cálcio $\left(\mathrm{Ca}^{++}\right)$e magnésio $\left(\mathrm{Mg}^{++}\right)$trocáveis e alumínio $(\mathrm{Al+++})$ extraível. Numa mesma alíquota, após a determinação do Al por titulação da acidez com $\mathrm{NaOH}$ 0,025 $\mathrm{N}$, foram determinados $\mathrm{Ca}$ e $\mathrm{Mg}$, com solução de EDTA 0,0125 M, e em outra somente Ca. Finalmente, os elementos $\mathrm{Ca}, \mathrm{Mg}$ e $\mathrm{Al}$ extraíveis foram determinados em espectrofotômetro de absorção atômica. Os teores de potássio $\left(\mathrm{K}^{+}\right)$ e sódio $\left(\mathrm{Na}^{+}\right)$trocáveis foram extraídos com $\mathrm{HCl}$ 0,05 N na proporção 1:10 e determinados por fotometria de chama, e a acidez extraível $\left(\mathrm{H}^{++} \mathrm{Al}+++\right)$ por titulação com solução de $\mathrm{NaOH}$ 0,0606 N, após extração com solução de acetato de cálcio $1 \mathrm{~N}$ ajustada a $\mathrm{pH} 7$, na proporção 1:15. Pela soma dos cátions básicos trocáveis $(\mathrm{Ca}, \mathrm{Mg}, \mathrm{K}$ e Na) obteve-se o valor da soma de bases (valor S), que acrescido da acidez extraível $(\mathrm{H}+\mathrm{Al})$ corresponde à capacidade de troca catiônica (valor T). Dividindo-se o valor $\mathrm{S}$ pelo valor $\mathrm{T}$, obteve-se a percentagem de saturação por bases (V\%). A saturação por alumínio (m) refere-se à proporção desse elemento em relação à somatória dos teores de cátions básicos trocáveis com o de alumínio extraível.

\begin{tabular}{|c|c|c|c|c|c|c|c|c|}
\hline $\begin{array}{c}\text { Número } \\
\text { do Prot. }\end{array}$ & Horiz. & $\begin{array}{c}\text { Profundidade. } \\
\mathbf{c m}\end{array}$ & $\begin{array}{c}\text { Areia } \\
\text { grossa } \\
\mathbf{2 . 0 0 - 0 . 2 0} \\
\mathbf{m m}\end{array}$ & $\begin{array}{c}\text { Areia fina } \\
\mathbf{0 . 2 0 - 0 . 0 5} \\
\mathbf{m m}\end{array}$ & $\begin{array}{c}\text { Areia total } \\
\mathbf{2 . 0 0 - 0 . 0 5} \\
\mathbf{m m}(\mathrm{g} / \\
\mathbf{k g})\end{array}$ & $\begin{array}{c}\text { Silte } \\
\mathbf{0 . 0 5 - 0 . 0 0 2} \\
\mathbf{m m}\end{array}$ & $\begin{array}{c}\text { Argila } \\
>0.002 \\
\mathbf{m m}\end{array}$ & $\begin{array}{c}\text { Argila } \\
\text { dispersa }^{\mathrm{s}} \\
\mathbf{> 0 . 0 0 2} \\
\mathbf{m m}\end{array}$ \\
\hline 1584 & $\mathrm{C}_{1}$ & $0-12$ & 603 & 150 & 753 & 174 & 73 & 35 \\
\hline 1585 & $\mathrm{C}_{2}$ & $12-(35-50)$ & 520 & 127 & 646 & 218 & 136 & 96 \\
\hline 1586 & $\mathrm{C}_{3}$ & $(35-50)-80$ & 291 & 135 & 426 & 450 & 124 & 8 \\
\hline 1587 & $\mathrm{C}_{4}$ & $80-105$ & 265 & 87 & 352 & 498 & 150 & 10 \\
\hline 1588 & $\mathrm{C}_{5}$ & $105-120$ & 394 & 98 & 492 & 402 & 107 & 15 \\
\hline 1589 & $\mathrm{~A}$ & $120-(125-135)$ & 398 & 148 & 546 & 348 & 106 & 7 \\
\hline 1590 & $\mathrm{AB}$ & $(125-135)-138$ & 439 & 232 & 671 & 231 & 98 & 16 \\
\hline 1591 & $\mathrm{BA}$ & $138-158$ & 450 & 233 & 683 & 227 & 91 & 68 \\
\hline 1592 & $\mathrm{~B}$ & $158+$ & 275 & 130 & 405 & 221 & 374 & 324 \\
\hline
\end{tabular}

$\$$ Argila dispersa somente em água sem a utilização de dispersantes químicos, também denominada argila natural.

Tabela 1. Caracterização granulométrica das diferentes camadas (horizontes) de um perfil de solo desenvolvido de um sambaqui (Sambaqui Moraes - Município de Miracatu - SP). 


\begin{tabular}{|c|c|c|c|c|c|c|c|c|c|c|c|c|c|c|c|c|c|c|}
\hline \multicolumn{3}{|c|}{ Identificação da amostra } & \multirow{2}{*}{$\begin{array}{c}\text { ph } \\
\mathrm{H}_{2} \mathrm{O}\end{array}$} & \multirow{2}{*}{$\begin{array}{c}\mathrm{ph} \\
\mathrm{KCl}\end{array}$} & c & m.o. & $\mathrm{p}$ & k & na & ca & $\mathrm{mg}$ & al & $\mathrm{h}+\mathrm{al}$ & $\mathrm{sb}$ & $\mathrm{t}$ & $\mathrm{t}$ & $\mathbf{v}$ & $\mathrm{m}$ \\
\hline Hor. & Profundidade $(\mathrm{cm})$ & Descrição & & & \multicolumn{2}{|c|}{$\mathrm{g} / \mathrm{Kg}$} & \multicolumn{3}{|c|}{$\mathrm{mg} / \mathrm{dm}^{3}$} & \multicolumn{7}{|c|}{$\mathrm{cmol} / \mathrm{dm}^{3}$} & \multicolumn{2}{|c|}{$\%$} \\
\hline $\mathrm{C}_{1}$ & $0-12$ & $\mathrm{C}_{1}$ & 7,01 & 6,40 & 13,46 & 23.15 & 311 & 49 & 12 & 6.54 & 0.77 & 0.00 & 2.19 & 7.49 & 7.49 & 9.68 & 77.40 & 0.00 \\
\hline $\mathrm{C}_{2}$ & $12-(35-50)$ & $\mathrm{C}_{2}$ & 6,58 & 6,20 & 17,73 & 30.49 & 697 & 74 & 84 & 9.67 & 0.53 & 0.00 & 3.20 & 10.75 & 10.75 & 13.95 & 77.10 & 0.00 \\
\hline $\mathrm{C}_{3}$ & $(35-50)-80$ & $\mathrm{C}_{3}$ & 8,51 & 8,15 & 13,82 & 23.77 & 85 & 20 & 19 & 7.98 & 0.08 & 0.00 & 0.16 & 8.19 & 8.19 & 8.35 & 98.10 & 0.00 \\
\hline $\mathrm{C}_{4}$ & $80-105$ & $\mathrm{C}_{4}$ & 8,44 & 8,22 & 15,75 & 27.08 & 119 & 21 & 18 & 7.91 & 0.1 & 0.00 & 0.75 & 8.14 & 8.14 & 8.89 & 91.50 & 0.00 \\
\hline $\mathrm{C}_{5}$ & $105-120$ & $\mathrm{C}_{5}$ & 8,47 & 8,24 & 13,83 & 23.79 & 78 & 21 & 18 & 8.22 & 0.15 & 0.00 & 0.39 & 8.50 & 8.50 & 8.89 & 95.70 & 0.00 \\
\hline $\mathrm{A}_{\mathrm{b}}$ & $120-(125-135)$ & A & 8,64 & 8,33 & 7,26 & 12.49 & 77 & 20 & 18 & 6.96 & 0.15 & 0.00 & 0.81 & 7.24 & 7.24 & 8.04 & 90.00 & 0.00 \\
\hline $\mathrm{AB}$ & $(125-135)-138$ & $\mathrm{AB}$ & 8,35 & 8,45 & 2,49 & 4.29 & 545 & 31 & 28 & 4.51 & 0.1 & 0.00 & 1.02 & 4.81 & 4.81 & 5.83 & 82.60 & 0.00 \\
\hline $\mathrm{BA}$ & $138 \cdot 158$ & BA & 8,37 & 8,39 & 0,90 & 1.55 & 371 & 25 & 12 & 3.79 & 0.1 & 0.00 & 0.22 & 4.01 & 4.01 & 4.23 & 94.70 & 0.00 \\
\hline B & $158^{+}$ & B & 8,19 & 7,67 & 1,25 & 2.15 & 95 & 23 & 10 & 9.16 & 0.19 & 0.00 & 0.12 & 9.45 & 9.45 & 9.57 & 98.80 & 0.00 \\
\hline
\end{tabular}

pH em água - relação 1:2,5,

CTC (t) - Capacidade de Troca Catiônica Efetiva; P, Na, K, Extrator Mehlich-1

CTC(T) - Capacidade de Troca Catiônica a pH 7,0

$\mathrm{Ca}, \mathrm{Mg}$ - Extrator $\mathrm{KCl} 1 \mathrm{~mol} / \mathrm{L}$

$\mathrm{V}$ - Índice de Saturação por Bases

$\mathrm{H}+\mathrm{Al}$ - Extrator Acetato de Cálcio 0,5 mol/L - pH 7,0

$\mathrm{m}$ - Indice de Saturação por Alumínio

SB - Soma de Bases Trocáveis

Matéria Orgânica (M.O) = C (carbono orgânico determinado pelo método Walkley - Black) x 1,724

Tabela 2. Caracterização química das diferentes camadas (horizontes) de um perfil de solo desenvolvido de um sambaqui (Sambaqui Moraes - Município de Miracatu - SP).

\begin{tabular}{|c|c|c|c|c|c|c|c|c|}
\hline Prot & Horiz. & $\begin{array}{c}\text { Prof. } \\
\mathrm{cm}\end{array}$ & $\begin{array}{c}\text { Areia grossa } \\
2.00-0.20 \\
\mathrm{~mm}\end{array}$ & $\begin{array}{c}\text { Areia fina } \\
0.20-0.05 \\
\mathrm{~mm}\end{array}$ & $\begin{array}{c}\text { Areia total } \\
2.00-0.05 \\
\mathrm{~mm}(\mathrm{~g} / \mathrm{kg})\end{array}$ & $\begin{array}{c}\text { Silte } \\
0.05-0.002 \\
\mathrm{~mm}\end{array}$ & $\begin{array}{c}\text { Argila } \\
>0.002 \mathrm{~mm}\end{array}$ & $\begin{array}{c}\text { Argila } \\
\mathrm{dispersa}^{\mathrm{S}} \\
>0.002 \mathrm{~mm}\end{array}$ \\
\hline 1593 & Ap & $0-2$ & 605.00 & 164.13 & 769.12 & 156.88 & 74.00 & 30.50 \\
\hline 1594 & $\mathrm{~A}$ & $2-20$ & 496.63 & 198.88 & 695.51 & 190.99 & 113.50 & 30.50 \\
\hline 1595 & $\mathrm{AB}$ & $20-30$ & 444.01 & 202.30 & 646.31 & 191.69 & 162.00 & 92.50 \\
\hline 1596 & BA & $30-60$ & 382.26 & 186.21 & 568.47 & 166.03 & 265.50 & 61.00 \\
\hline 1597 & B & $70^{+}$ & 304.22 & 115.48 & 419.70 & 104.30 & 476.00 & 12.00 \\
\hline
\end{tabular}

§ Argila dispersa somente em água sem a utilização de dispersantes químicos, também denominada argila natural.

Tabela 3. Caracterização granulométrica de um perfil de Argissolo Vermelho Amarelo no Município de Miracatu - SP.

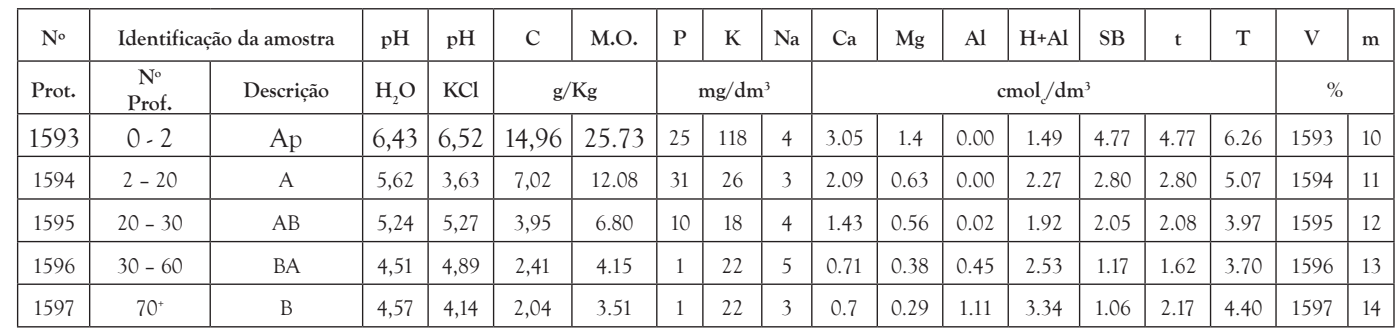

pH em água - relação 1:2,5,

CTC (t) - Capacidade de Troca Catiônica Efetiva; P, Na, K, Extrator Mehlich-1

CTC(T) - Capacidade de Troca Catiônica a pH 7,0

$\mathrm{Ca}, \mathrm{Mg}$ - Extrator $\mathrm{KCl} 1 \mathrm{~mol} / \mathrm{L}$

$\mathrm{V}$ - Índice de Saturação por Bases

$\mathrm{H}+\mathrm{Al}$ - Extrator Acetato de Cálcio 0,5 mol/L - pH 7,0

$\mathrm{m}$ - Índice de Saturação por Alumínio

SB - Soma de Bases Trocáveis

Matéria Orgânica (M.O) = C (carbono orgânico determinado pelo método Walkley - Black) x 1,724

Tabela 4. Caracterização granulométrica de um Argissolo Vermelho e Amarelo no Município de Miracatu - SP. 


\begin{tabular}{|c|c|c|c|c|c|c|}
\hline \multirow{2}{*}{$\begin{array}{c}\text { Número } \\
\text { do Prot. }\end{array}$} & \multirow{2}{*}{ Horiz. } & Profundidade. & \multicolumn{2}{|c|}{$\mathrm{CaO}$} & $\mathrm{MgO}$ & \multicolumn{2}{|c|}{$\mathrm{Ca}$} & $\mathrm{Mg}$ \\
\cline { 3 - 7 } & $\mathrm{cm}$ & \multicolumn{3}{|c|}{$\%$} & \multicolumn{2}{c|}{ cmolc dm-3 } \\
\hline 1584 & $\mathrm{C} 1$ & $0-12$ & 0,55 & 0,38 & 19,68 & 18,38 \\
\hline 1585 & $\mathrm{C} 2$ & $12-(35-50)$ & 5,11 & 0,55 & 186,25 & 27,09 \\
\hline 1586 & $\mathrm{C} 3$ & $(35-50)-80$ & 27,57 & 0,55 & 971,29 & 26,80 \\
\hline 1587 & C 4 & $80-105$ & 31,36 & 0,43 & 1118,98 & 21,15 \\
\hline 1588 & C 5 & $105-120$ & 24,02 & 0,45 & 848,54 & 22,07 \\
\hline 1589 & A & $120-(125-135)$ & 16,58 & 0,33 & 582,73 & 16,10 \\
\hline 1590 & AB & $(125-135)-138$ & 3,01 & 0,17 & 109,36 & 8,12 \\
\hline 1591 & BA & $138-158$ & 0,54 & 0,13 & 19,63 & 6,29 \\
\hline 1592 & B & $158+$ & 0,53 & 0,35 & 18,31 & 16,66 \\
\hline 1594 & A & $2-(15-23)$ & 0,12 & 0,04 & 4,66 & 1,83 \\
\hline
\end{tabular}

§ Argissolo Vermelho Amarelo Adjacente.

Tabela 5. Determinação do total dos teores de cálcio e magnésio em amostras de diferentes camadas (horizontes) de um perfil desenvolvido de um sambaqui.

\section{Resultados e discussão}

Foram retiradas cinco amostradas do perfil de solo desenvolvido no sambaqui Moraes denominadas de A1 até A5 separadas no campo por diferenças de cor, textura e estrutura (Anexo 1). As camadas de deposição antrópica vão até a profundidade de 105 a $120 \mathrm{~cm}$ de profundidade num transição ondulada, sendo este horizonte provavelmente a superfície original do solo, sem influência antrópica denominada na descrição de $A_{b}$, o subscrito (b) denota um horizonte enterrado (buried) o que provavelmente é a situação deste horizonte A do solo neste local (Fig.5).

Supõe-se que quando as populações sambaquieiras começaram a depositar ossos de animais e sepultamentos humanos neste local este teria sido o horizonte superficial. Este processo de amontoamento se iniciou há mais de 6000 anos AP tendo sido gradativo com datações nas camadas mais superiores mostrando uma ocupação deste local por mais de 2000 anos (Plens 2009).

Os teores de argila do horizonte $\mathrm{Ab}$ (Tabela 1) apresenta valores similares ao horizonte $A$ do solo adjacente (Tabela 3) (Anexo 2), os valores de vários parâmetros químicos provavelmente alterados pelo processo contínuo de lixiviação e migração do material depositado, tendo causado uma grande variação nos valores originais em comparação com o solo sem influência antrópica encontrados nesta região. Estas alterações ficam bastante evidenciadas (Tabela 2 e 4) nos valores de $\mathrm{pH}$ que nos horizontes de solo desenvolvido no sambaqui adquiriram um carácter de alcalinidade $(\mathrm{pH}>7,1)$ e também aumento nos teores de fósforo assimilável $\left(\mathrm{P}_{\text {ass }}\right.$.) e cálcio trocável $\left(\mathrm{Ca}_{\mathrm{t}}\right)$, este efeito de aumento dos valores de $\mathrm{pH}$ e enriquecimento com $\mathrm{P}_{\text {ass }}$ e $\mathrm{Ca}_{\mathrm{t}}$ é evidente até a maior profundidade amostrada $(\sim 1,50$ m). O carácter alcalino também foi verificado no sambaqui estudado por Zuliani et al. (2005) assim como os elevados teores de $\mathrm{P}_{\text {ass }}$ e $\mathrm{Ca}_{\mathrm{t}}$.

Os teores foram elevados de $\mathrm{P}_{\text {ass }}$ em todas as camadas com influência antrópica, entretanto, o mesmo apresenta grande variabilidade nas diferentes camadas. Esta variabilidade pode indicar uma atividade antrópica diferenciada nas diferentes fases. $\mathrm{O}$ aumento do $\mathrm{P}$ em áreas antropizadas se dá principalmente pelo aporte de resíduos de apatita biogênica (ossos) e o acúmulo de $\mathrm{P}$ em algumas camadas pode indicar períodos de maior atividade de concentração destes resíduos. Os teores de aproximadamente $700 \mathrm{ppm}$ de $\mathrm{P}_{\text {ass }}$ na camada C2 pode indicar que a atual superfície do sambaqui foi local de intensa concentração de resíduos. Es- 


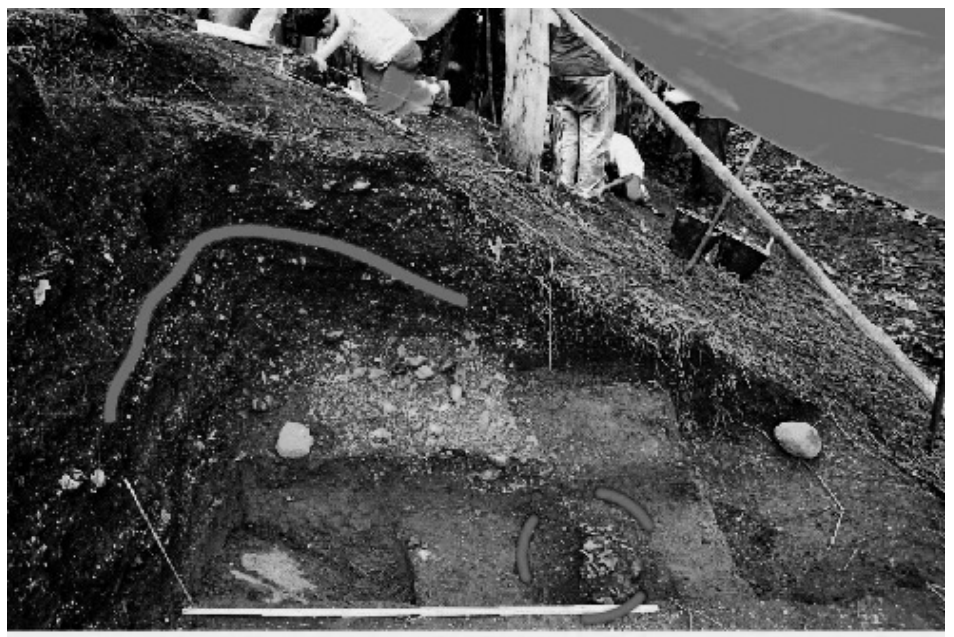

Fig. 5. Detalhe do perfil de solo desenvolvido de depósitos de conchas (sambaqui fluvial) no município de Miracatu - SP.

tudos comprovando a origem biogênica do $\mathrm{P}$ nos sambaqui também deverá ser objeto de pesquisa.

Os teores de $\mathrm{Ca}$ no perfil apresentaram valores elevados em comparação com o solo adjacente, principalmente nas camadas mais profundas. Entretanto estes valores de Ca ficaram abaixo do esperado, dada a natureza química das conchas utilizadas no sambaqui, que são compostas principalmente de carbonato de cálcio (Fig. 6). As diferentes amostras foram então analisadas para determinação dos teores de cálcio total (Tabela 5). Esta metodologia é mais apropriada para análise dos horizontes dos sambaquis permitindo diferenciar de forma mais evidente as áreas de concentração das conchas de outras camadas sem deposição de material conchífero, mas com aumento dos teores de $\mathrm{Ca}$, devido à lixiviação e acúmulo de cálcio na forma iônica e não devido à deposição. Este fenômeno é o que provavelmente ocorreu nos horizonte $\mathrm{AB}, \mathrm{BA}$ e $\mathrm{B}$.

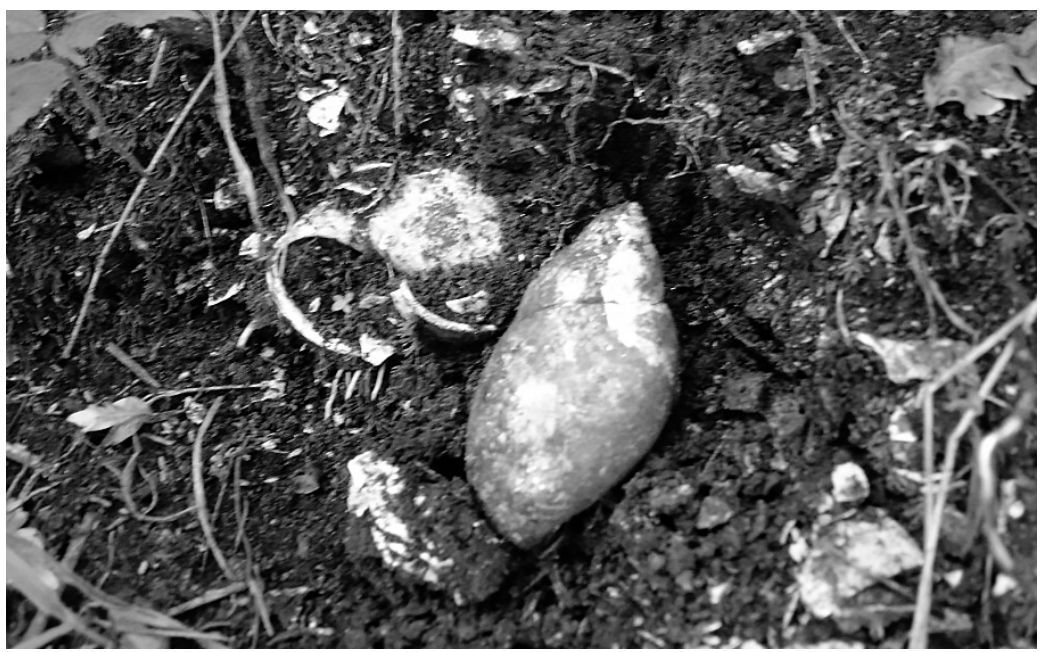

Fig. 6. Detalhe do principal caramujo (Megalobulimus spp.) componente do sítio Moraes, município de Miracatu - SP. 
Um fato observado são os elevados teores de carbono neste perfil até a profundidade de $1 \mathrm{~m}$. Os mecanismos de estabilização e o armazenamento do carbono nos sambaquis são um fenômeno ainda a ser elucidado. Processos envolvendo a estabilização da matéria orgânica pelos elevados teores de cálcio disponíveis e a contribuição de formas de carbono de origem pirogênica (black carbon), a exemplo do que ocorre nas Terras Pretas de Índio, necessitam ser investigados. Os mecanismos de acúmulo de carbono nos sambaquis podem ser similares aos que ocorrem nos horizontes chernozenicos onde a origem pirogênica tem menor influência, estando a estabilização do carbono ligada aos elevados teores de cálcio.

\section{Processos pedogenéticos envolvidos}

O perfil estudado apresenta uma evolução condicionada principalmente pelo acúmulo de material com elevados teores de carbonato de cálcio (conchas) e material rico em fósforo, como os ossos de animais.

Os materiais analisados das diferentes camadas mostram desuniformidade quanto ao percentual de distribuição das frações da areia entre as duas amostras superficiais $\left(A_{1}\right.$ e $\left.A_{2}\right)$ e o material sobrejacente. Isto demonstra uma descontinuidade do material indicando uma alteração do substrato que formou estes horizontes. Principalmente os maiores teores de areia grossa podem ser material oriundo de processos erosivos, processos acumulativos pela migração e destruição das argilas e material depositado pelas populações sambaquieiras. Estudos sobre os percentuais de areia grossa em solos desenvolvidos nesta posição da paisagem (área de inundação do ribeirão dos Moraes) poderão elucidar algumas destas hipóteses.
A partir da constatação de teores de fósforo muito mais elevados que o do perfil de solo circundante supõe-se o enriquecimento da camada superficial pelas populações sambaquieiras pelo acúmulo de fontes ricas em P. Os elevados teores de carbono neste sítio provavelmente têm um mecanismo diferente dos horizontes antrópicos das Terras Pretas de Índio (TPI) devendo ser relacionados adicionalmente a prováveis efeitos pirogênicos de fogueiras (embora não tenha sido localizada nenhuma estrutura associada a fogueira dentro do sítio) e à elevada disponibilidade de cálcio proveniente de conchas que estabilizaria a matéria orgânica (Lützow et al. 2006; Oades 1988). A presença desses elevados teores de $\mathrm{P}$ no horizonte superficial poderá ser utilizada como um indicador de atividades antrópicas nas diferentes fases evolutivas do sítio, entretanto, análises dos teores de $\mathrm{P}$ total poderão ser mais indicativas que os teores de $\mathrm{P}$ disponível como o realizado neste estudo.

\section{Agradecimentos}

Agradecimentos à Fundação de Amparo à Pesquisa do Estado de São Paulo pelo financiamento do projeto "O estudo dos sambaquis fluviais das bacias do médio Juquiá, São Lourenço e do Itariri." (Prof. Dr. Levy Figuti MAE/USP - FAPESP. Processo no. 05/50078-0); ao Programa Alban pela bolsa de doutorado sanduíche de Cláudia Regina Plens (Código Alban E05D050329BR); à Embrapa Solos, pelo financiamento das análises laboratoriais dentro do Projeto Terra Preta - Embrapa Solos); aos pesquisadores Emilio Antunes e Edgar Shinzato (CPRM - Rio de Janeiro), pelo auxílio na coleta e nomenclatura da descrição dos perfis, e aos professores Drs. Paulo DeBlasis, Eduardo Góes Neves e Marisa Coutinho Afonso, do Museu de Arqueologia e Etnologia da Universidade de São Paulo, pelas críticas e comentários. 
TEIXEIRA, W.G.; PLENS, C.R.; MACEDO, R.S.; FIGUTI; L. Characterization of soil profile developed in a riverine shellmound (Sambaqui Moraes), Miracatu-SP, Brasil. R. Museu Arq. Etn., São Paulo, n. 22: 181-194, 2012.

\begin{abstract}
Archaeological excavations carried out in the riverine shellmound Moraes, Miracatu, SP - Brazil, pointed out distinct archaeological layers which resulted in the mound configuration of the site. Therefore, aiming at reaching a first approach on the formation process of the site, physical-chemical soil analysis from inside and outside the site were developed in order to comprehend the properties that could have contributed for the characterization of the peculiarities found on the archaeological layers of this riverine shellmound. It was demonstrated a large alteration in many chemical and physical properties of the soil horizons developed in the shellmound. The high levels of phosphorus in the dark horizons indicate an enrichment of that horizon by addition of residues rich in this element (e.g. bones). The dark horizons also show high levels of organic carbon in comparison with the original soil horizon. However, if the stabilization of the organic carbon that allows its accumulation in the dark horizons of shellmonds is because formation of stable compound with calcium and/or effect of heating (pyrogenic carbon) it is not clear and should be further investigated.
\end{abstract}

Keywords: Riverine shellmounds, Soil analysis, Dark soil, Formation process, Hunter-gatherers.

\title{
Referências bibliográficas
}

CAMARGO, O.A.; MONIZ, A.C.; JORGE, J.A.; VALADARES, J.M.A.S.

1986 Métodos de análise química, mineralógica e física de solos do Instituto Agronômico do Estado de São Paulo. Campinas (Boletim técnico, 106).

CPRM

2001 Geologia, Tectônica e Recursos Minerais do Brasil: Sistema de Informações Geográficas - SIG e Mapas na escala 1: 25000.000. Brasilia: CPRM (CD ROM).

\section{EMBRAPA.}

1997 Centro Nacional de Pesquisa de Solos. Manual de métodos de análise de solo. Rio de Janeiro (EMBRAPA-CNPS. Documentos, 1).

FIGUTI, L.

2006 Investigações arqueológicas e geofísicas dos sambaquis fluviais do vale do Ribeira de Iguape, Estado de São Paulo. Relatório Final de atividades de projeto temático. FAPESP no 1999/12684-2. MAE/ USP.
GASPAR, M

1998 Considerations of the sambaquis of the Brazilian coast. Antiquity Special Section: Issues in Brazilian archaeology, 72 (277): 592-615.

2004 Sambaqui: arqueologia do litoral brasileiro. Rio de Janeiro: Jorge Zahar.

HECKENBERGER, M.

2001 Estrutura, história e transformação: a cultura Xinguana na longue durée, 1000-2000 d.C.. In: Franchetto, B.; Heckenberger, M. (Orgs.) Os povos do Alto Xingu - história e cultura. Rio de Janeiro, Editora da UFRJ: 21-62.

LEMOS, R.C.; SANTOS, R.D.

1996 Manual de descrição e coleta de solo no campo. Campinas: Sociedade Brasileira de Ciência do Solo.

LEPSCH, I.F.; PRADO, H.; MENK, J.R.F.; SAKAI, E.; RIZZO, L.F.

1999 Levantamento de reconhecimento com detalhes 
da região do Rio Ribeira de Iguape no Estado de São Paulo. Mapa avulso- Instituto Agronômico e Instituto de Geociências de São Paulo. Campinas: Instituto Agronômico.

LUTZOW, M.V.; KOEGEL-KNABNER, I.; EKSCHMITT, K.; MATZNER, E. GUGGENBERGER, G.; MARSCHNER, B.; FLESSA, H.

2006 Stabilization of organic matter in temperate soils: Mechanisms and their relevance under different soil conditions: a review. Eur. J. Soil Sci., 57: 426-445.

OADES, J.M.

1988 The retention of organic matter in soils. PLENS, C.R. Biogeochemistry, 5: 35-70.

2007 O Sítio Moraes: Uma Biografia Não Autorizada. Tese de Doutorado. São Paulo, Museu de Arqueologia e Etnologia da Universidade de São Paulo.

2009 O papel dos amontoados de conchas no sambaqui fluvial. Revista de Arqueologia
(Sociedade de Arqueologia Brasileira), 22: 77-93.

2010 Animals for human in life and death. Revista do Museu de Arqueologia e Etnologia, 20: 30-51.

PROUS, A.

1992 Arqueologia Brasileira. Universidade de Brasília.

SAKAY, E.; LEPSCH, I.F.

1987 Levantamento pedológico detalhado e distribuição espacial de características dos solos do pôlder Registro - I, SP. Boletim cientifico do Instituto Agronômico, Campinas, IAC. 56 p.

TEIXEIRA, W.G.; KERN, D.C. MADARI, B.E.; LIMA, H.N.; WOODS, W. (EDS).

2010 As Terras Pretas de Índio da Amazônia: sua caracterização e uso deste conhecimento na criação de novas áresas. Manaus: Edua/EMBRAPA. $420 p$ 


\section{ANEXO 1}

\section{A. Descricão Geral do Ambiente}

\section{PERFIL 1}

Data - 30/05/06

Classificação - Argissolo Amarelo A antrópico, textura ...

Localização, Município, Estado e Coordenadas - Fazenda do Sr., município de Miracatu-SP. Coordenadas: - 24,27 S e 47,39 W (Lat / Long - graus decimais) e 23J 0256908 / 7313340 - UTM (Datum - WGS 84).

Situação, Declive e Cobertura Vegetal Sobre o Perfil - Perfil aberto em corte de estrada, em relevo plano, com declive inferior a 3\%, na planície de inundação do ribeirão dos Moraes, com vegetação de gramíneas e circundado por um bananal.

Altitude - (GPS).

Litologia - Gnaisse e sedimentos colúvio-aluvionares.

Formação Geológica - Província Mantiqueira - Complexo Embu.
Cronologia - Proterozoico (complexo Embu) e depósitos colúvio-aluvionares do Quaternário (Holoceno).

Material Originário - Intemperismo do gnaisse e deposições de material colúvio-aluvionar e de material orgânico - ossos e material trazido pelos sambaquieiros, principalmente caramujos do gênero Mycrobolonys.

Pedregosidade - Ligeiramente pedregosa.

Rochosidade - Ligeiramente rochosa afloramento de rochas graníticas.

Relevo Local - Plano a suave ondulado.

Relevo Regional - Ondulado e forte ondulado.

Erosão - Laminar moderada.

Drenagem - Bem drenado nas primeiras camadas e moderada nos horizontes B.

Vegetação Primária - Floresta pluvial atlântica.

Uso Atual - Sem uso - Sítio Arqueológico - Sambaqui Moraes.

Clima - Af (Köeppen).

Descrito e Coletado por - Wenceslau Geraldes Teixeira, Cláudia Plens e Emílio Antunes.

\section{B. Descrição Morfológica}

0-12 cm, bruno-avermelhado-escuro (5YR 3/2, úmido); Textura; fraca, muito pequena granular; muito friável, não plástica e não pegajosa; transição plana e abrupta.

12-(35-50) cm, bruno-avermelhado (5YR 4/3, úmido); Textura; fraca, pequena e média, blocos subangulares; muito friável, não plástica e não pegajosa; transição ondulada e clara.

(35-50) - 80 cm, bruno-escuro (10YR 3/3, úmido); Textura; moderada, média e grandes blocos subangulares; muito friável, plástica e ligeiramente pegajosa; transição plana e clara.

80 - 105 cm, bruno-acinzentado-escuro (10YR 4/2, úmido); Textura; moderada, média e grande, blocos subangulares; plástica e pegajosa; transição plana e clara.

105 - 120 cm, bruno-amarelado-escuro (10YR 4/4, úmido); Textura; moderada, média e grande, blocos subangulares; plástica e pegajosa; transição plana e clara.

120 - (125-135) cm, bruno-amarelado-escuro (10YR 3/4, úmido); Textura; moderada, média e grandes blocos subangulares; plástica e pegajosa; transição ondulada e clara.

(125-135) - $138 \mathrm{~cm}$, bruno-amarelado-escuro (10YR 4/4, úmido); Textura; moderada, grande

$\mathrm{Ab} \quad$ a muito grandes blocos subangulares; ligeiramente plástica e ligeiramente pegajosa; transição ondulada e clara.

138 - 158 cm, (2YR 5/2, úmido); Textura; forte, grande a muito grande, blocos subangulares; ligeiramente plástica e ligeiramente pegajosa; transição ondulada e clara.

$158 \mathrm{~cm}^{+}$, bruno-amarelado (10YR 5/6, úmido); Textura; forte, grande a muito grande, blocos angulares; muito plástica e pegajosa.

O horizonte $\mathrm{Ab}$ se refere provavelmente ao horizonte $\mathrm{A}$ original do solo antes do início da deposição das conchas. 


\section{A. Descrição geral do ambiente}

\section{PERFIL 02}

Data - 30/05/06

Classificação - Argissolo amarelo antrópico

Localização, Município, Estado e Coordenadas - Fazenda do Sr. Celso Ferreira, município de Miracatu-SP. Coordenadas: - 24,27 S e 47,39 W (Datum - WGS 84).

Situação, Declive e Cobertura Vegetal Sobre o Perfil - Perfil de barranco. Perfil descrito próximo a plantio de banana.

Altitude - 30m (GPS).

Litologia - Gnaisse.

Formação Geológica - Província Mantiqueira - Complexo Embu.

\author{
Cronologia - Proterozoico (complexo \\ Embu). \\ Material Originário - Intemperismo do \\ gnaisse. \\ Pedregosidade - Não pedregosa. \\ Rochosidade - Ligeiramente rochosa. \\ Relevo Local - Forte e ondulado. \\ Relevo Regional - Ondulado. \\ Erosão - Laminar moderada. \\ Drenagem - Bem drenado. \\ Vegetação Primária - Floresta pluvial \\ tropical. \\ Uso Atual - Bananal. \\ Clima - Af (Köppen). \\ Descrito e Coletado por - Wenceslau Ge- \\ raldes Teixeira, Cláudia Plens e Emílio Antunes.
}

\section{B. Descrição morfológica}

0-2 cm, bruno-acinzentado-escuro (2,5Y 4/2, úmido); Textura; fraca, muito pequena granular; solta, não plástica e pegajosa; transição plana e clara.

2. $20 \mathrm{~cm}$, bruno (10YR 4/3, úmido); Textura; fraca, pequena blocos subangulares; muito friável, ligeiramente plástica e ligeiramente pegajosa; transição ondulada e clara.

20 - 30 cm, (2Y 4/3, úmido); Textura; moderada, média, blocos subangulares; friável, plástica e pegajosa; transição irregular e gradual.

30 - 60 cm, amarelo-brunado (10YR 6/8, úmido); Textura; moderada, média e grande blocos

BA subangulares; cerosidade moderada e comum; friável, plástica e pegajosa; transição ondulada e difusa. 